\title{
Thyroid hormone and the central control of homeostasis
}

\author{
Amy Warner and Jens Mittag \\ Department of Cell and Molecular Biology, Karolinska Institutet, von Eulers väg 3, 17177 Stockholm, Sweden
}

(Correspondence should be addressed to J Mittag; Email: jens.mittag@ki.se)

\begin{abstract}
It has long been known that thyroid hormone has profound direct effects on metabolism and cardiovascular function. More recently, it was shown that the hormone also modulates these systems by actions on the central autonomic control. Recent studies that either manipulated thyroid hormone signalling in anatomical areas of the brain or analysed seasonal models with an endogenous fluctuation in hypothalamic thyroid hormone levels revealed that the hormone controls energy turnover. However, most of these studies did not progress beyond the level of anatomical nuclei; thus, the neuronal substrates as well as the molecular mechanisms remain largely enigmatic. This review summarises the evidence for a role of thyroid hormone in the central autonomic control of peripheral homeostasis and advocates novel strategies to address thyroid hormone action in the brain on a cellular level.
\end{abstract}

Journal of Molecular Endocrinology (2012) 49, R29-R35

\section{Introduction}

Thyroid hormone has long been known for its profound effects on the metabolic rate and cardiovascular function (Magnus-Levy 1895, Klein \& Ojamaa 2001). This becomes most evident in hyperthyroidism, which is accompanied by an increased metabolic rate and weight loss despite increased food intake as well as tachycardia (Klein \& Ojamaa 2001, Kim 2008, Sainsbury \& Zhang 2011). Conversely, weight gain and bradycardia are observed in hypothyroid patients (Kim 2008). Most of these effects have been attributed to the direct actions of thyroid hormones in the corresponding peripheral tissues such as the heart (Kahaly \& Dillmann 2005) or metabolically active tissues such as skeletal muscle or fat (Short et al. 2001, Silva 2006). Several cellular mechanisms have been identified in these tissues (Short et al. 2001), which can explain the observed effects on the molecular level. However, recently, the concept has emerged that thyroid hormone also modulates these processes via one of its main target tissues - the brain (Fliers et al. 2010). This review summarises the currently available information on the actions of thyroid hormone in the brain with a focus on its interactions with the autonomic nervous system regulating metabolic and cardiovascular functions (see overview in Table 1).

Journal of Molecular Endocrinology (2012) 49, R29-R35

0952-5041/12/049-R29 (c) 2012 Society for Endocrinology Printed in Great Britain

\section{Regulation of cellular thyroid hormone signalling}

The main forms of thyroid hormone secreted by the thyroid gland are tetraiodothyronine $\left(\mathrm{T}_{4}\right)$ and 3,3', 5-triiodothyronine $\left(\mathrm{T}_{3}\right) . \mathrm{T}_{4}$ has little biological activity by itself and is considered a prohormone, as activation occurs through outer ring deiodination to $\mathrm{T}_{3}$, the active form of thyroid hormone. The deiodination process is carried out by deiodinase type II (Dio2) or Diol (Bianco \& Kim 2006). $\mathrm{T}_{3}$ and $\mathrm{T}_{4}$ can also be inactivated by inner ring deiodination carried out by Dio3 or Dio1, which leaves $T_{2}$ and reverse $T_{3}$ respectively. Whether these forms of thyroid hormone have inherent biological activity is still a matter of debate.

The level of deiodinase expression modulates the cellular availability of thyroid hormone. For instance, in activated brown fat, high levels of thyroid hormone are required for the upkeep of facultative thermogenesis a condition that is achieved by the high expression of Dio2. Conversely, tissues that need protection from thyroid hormone express high levels of Dio3, e.g. the placenta, which shields the early developing embryo from overexposure to the hormone (Huang 2005).

Another level of regulation is the uptake of thyroid hormone into target organs or cells. While a few years ago it was still assumed that thyroid hormone can enter

DOI: 10.1530/JME-12-0068 Online version via http://www.endocrinology-journals.org 
Table 1 Summary of the central effects of thyroid hormone discussed in this review focussing on energy expenditure and uptake, seasonal adaptations and cardiovascular function

\begin{tabular}{|c|c|c|}
\hline Affected system & Type of action & Consequence of central action \\
\hline \multirow[t]{2}{*}{ Energy expenditure } & & $\begin{array}{l}\text { Thyroid hormone stimulates sympathetic output to brown fat } \\
\text { (thermogenesis } \uparrow \text { ) and liver (gluconeogenesis } \uparrow \text { ) }\end{array}$ \\
\hline & Developmental & Developmental hypothyroidism causes defective metabolic set point \\
\hline Energy uptake & Acute & Thyroid hormone increases food intake via the hypothalamus \\
\hline Body weight and reproduction & Seasonal & $\begin{array}{l}\text { Modulation of hypothalamic thyroid hormone levels is needed for } \\
\text { seasonal adaptations, e.g. body weight }\end{array}$ \\
\hline Cardiovascular & Acute/developmental & $\begin{array}{l}\text { Thyroid hormone interferes with the autonomic nervous system causing } \\
\text { maladaptation upon stress, changes in temperature, activity, etc. }\end{array}$ \\
\hline
\end{tabular}

cells by passive diffusion through the cell membrane due to its lipophilic properties, this view has changed with the discovery of very specific hormone transporters such as the monocarboxylate transporter 8 (MCT8 (SLC16A2)) or organic-anion-transporting-polypeptide 1c1 (OATP1c1, OATP14) (Friesema et al. 2005, Visser et al. 2011). These molecules are essential for the uptake of thyroid hormones, which is impressively underlined by the observation that in the absence of MCT8, no significant amounts of $\mathrm{T}_{3}$ can enter the brain (Dumitrescu et al. 2006, Trajkovic et al. 2007).

The final level of thyroid hormone signalling control is given by the expression of nuclear thyroid hormone receptors encoded by the genes THRA and THRB (Yen et al. 2006). These two genes give rise to several isoforms. The isoforms TR $\alpha 1$ and TR $\beta$ are regular thyroid hormone receptors, which bind DNA and $\mathrm{T}_{3}$ and regulate transcription of target genes. By contrast, the isoform $\mathrm{TR} \alpha 2$ does not bind $\mathrm{T}_{3}$ and probably constitutes another level of thyroid hormone signalling regulation as an antagonist (Yen 2001, Mittag et al. 2005, Yen et al. 2006). The functional TRs mediate the vast majority of thyroid hormone actions on the level of gene transcription; however, so-called non-genomic effects using other target molecules have been reported as well (Davis \& Davis 1996).

Taken together, the activating and inactivating deiodinases, the specific transporters and the different receptor isoforms represent a fine regulatory system of cellular thyroid hormone signalling, somewhat independent of the levels of circulating hormone. More importantly, these elements can constitute specific genetic tools to manipulate thyroid hormone signalling on the cellular level using gain- or loss-of-function approaches.

\section{Thyroid hormone acts developmentally and acutely in the brain}

Thyroid hormone is of utmost importance for both the development and the maintenance of brain function (Bernal 2007). Disturbances in thyroid hormone signalling during embryonal and early postnatal development can cause permanent defects in brain architecture (de Escobar et al. 2007), which persist into adulthood. In addition, transient alterations in thyroid hormone signalling in the adult also interfere with brain function; in contrast to developmental defects, however, these changes are usually reversible by appropriate treatment (Bernal 2007). Thus, when analysing the effects of thyroid hormone on peripheral homeostasis via the brain, it needs to be clearly established whether the observed phenotype is the consequence of a permanent developmental defect or an acute action of thyroid hormone. Often this information can be derived from the experimental or clinical paradigm, but in cases of congenital genetic problems - such as defects in thyroid hormone transport, activation or signalling - both aspects can overlap. This consequently results in a complex phenotype at different levels of homeostatic regulation mixing developmental and acute hormone actions.

\section{Thyroid hormone modulates metabolism via the brain}

The most investigated effects of thyroid hormone on the central control of homeostasis in rodents are those on metabolism and brown fat thermogenesis. Here, both developmental and acute actions of the hormone have been observed:

- Mice with a mutant thyroid hormone receptor $\alpha 1$ show a profound hypermetabolism as a consequence of central brown fat overactivation (Sjogren et al. 2007). This hypermetabolic phenotype originates in embryonic brain development (Vujovic et al. 2009), where defective thyroid hormone receptor signalling seems to interfere with the proper establishment of the hypothalamic thermostat. As a consequence, the sympathetic drive to the brown fat is increased, which stimulates thermogenesis and energy expenditure in this tissue by a yet unknown mechanism independent of $U C P 1$, as this gene was 
found to be unaltered (Sjogren et al. 2007). A similar hypermetabolic phenotype has later also been observed in offspring from maternally hypothyroxinaemic sheep (Forhead et al. 2009); however, a recently found patient with a mutation in TR $\alpha 1$ showed a borderline high body mass index (Bochukova et al. 2012). As this was also observed in a different TR $\alpha 1$ animal model (Liu et al. 2003), it seems that different mutations in TR 1 might give rise to different metabolic phenotypes - probably by altering the receptor's ability to interact with other nuclear coregulators.

- Acute hyperthyroidism is also associated with increased energy expenditure as well as hyperphagia in rodents (Lopez et al. 2010). Complex studies have been conducted to disassociate the central $\mathrm{T}_{3}$ actions from its well-known peripheral effects (for a review see Mittag (2009)): injections of thyroid hormone into the arcuate nucleus increase food intake by up-regulating mammalian target of rapamycin (mTOR) and consequently increased mRNA levels of the orexigenic agouti-related protein (AGRP) and neurpoeptide Y (NPY) as well as decreased expression of the anorexigenic pro-opiomelanocortin (POMC; Varela et al. 2012). When injected into the ventromedial hypothalamus, they decrease the activity of the hypothalamic AMP-activated protein kinase (AMPK), thus increasing energy expenditure via stimulating brown fat thermogenesis through the sympathetic nervous system (Lopez et al. 2010). In the paraventricular nucleus, thyroid hormone elevates hepatic endogenous glucose production via the sympathetic nervous system (Klieverik et al. 2009). Although some of the underlying molecular targets have been identified (Fig. 1), many questions on the cellular and molecular level remain to be elucidated.

\section{Thyroid hormone modulates seasonality via the brain}

A different animal model that has and will no doubt continue to provide new insight into the central metabolic actions of thyroid hormone is the Siberian hamster (Warner et al. 2010). In contrast to the advanced but very interventive mouse/rat models, this rodent endogenously modulates hypothalamic thyroid hormone levels in adjustment to changing seasons.
A

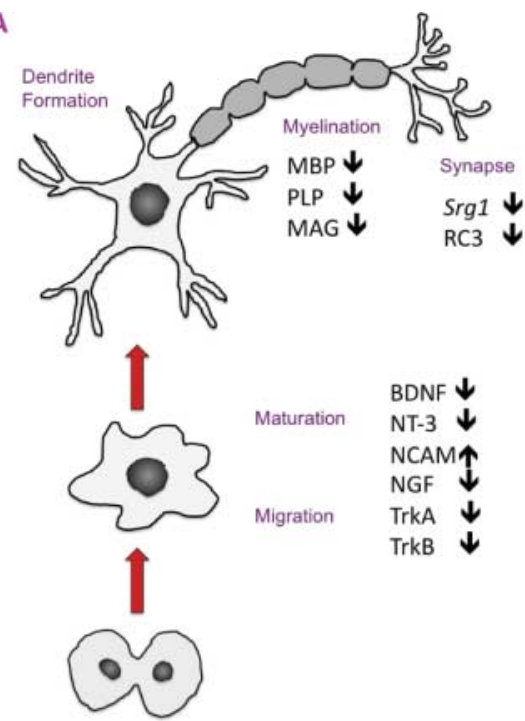

DEVELOPMENTAL HYPOTHYROIDISM
B

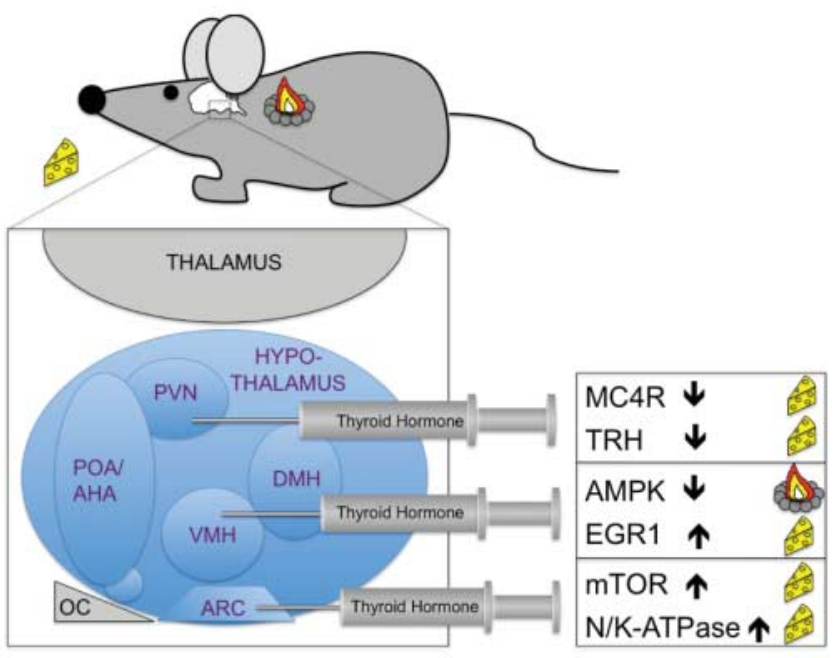

ADULT HYPERTHYROIDISM

Figure 1 Developmental and acute targets of thyroid hormone in the brain. Identified targets of thyroid hormone during neuronal development $(A)$ or in the adult hypothalamus $(B)$, which may explain the effects of the hormone on central homeostasis. $(A)$ Genes affected by developmental hypothyroidism (arrows indicate the directional effect of developmental hypothyroidism on gene expression; Alvarez-Dolado et al. 1994, Thompson and Potter 2000). (B) Genes found to be regulated by hypothalamic hyperthyroidism (arrows indicate directional effect of $\mathrm{T}_{3}$; Lechan and Fekete 2006, Decherf et al. 2010, Lopez et al. 2010, Varela et al. 2012). Trk, neurotrophic tyrosine kinase receptor; NGF, nerve growth factor; NCAM, neural cell adhesion molecule; NT-3, neurotrophin 3; BDNF, brain-derived neurotrophic factor; MBP, myelin basic protein; PLP (PLP1), proteolipid protein 1; MAG, myelin-associated glycoprotein; Srg1, synaptotagmin-related gene 1; RC3, neurogranin; MC4R, melanocortin 4 receptor; $\mathrm{TRH}$, thyrotropin releasing hormone; AMPK, AMP kinase; EGR1, early growth response protein 1; mTOR, mammalian target of rapamycin; N/K-ATPase, sodium-potassium ATPase; $\mathrm{POA} / \mathrm{AHA}$, preoptic area/anterior hypothalamic area; OC, optic chiasm; PVN, paraventricular nucleus of the hypothalamus; VMH, ventromedial hypothalamus; ARC, arcuate nucleus of the hypothalamus; $\mathrm{DMH}$, dorsomedial hypothalamus. 
Seasonality is an essential process for some species living in temperate or polar conditions, allowing the animal to anticipate the changing demands of the environment and to alter their physiology and behaviour accordingly. Studies on several photoresponsive species have shown an association between seasonality and local availability of $\mathrm{T}_{3}$ in the hypothalamus, and more specifically, a correlation in expression of genes encoding for Dio2 and Dio3, generally leading to a reduction in hypothalamic $\mathrm{T}_{3}$ in a short day length (SD) across species, regardless of the species-specific enzyme levels (reviewed in Ebling (2010)). In the Siberian hamster, the use of hypothalamic implants providing a constant release of $\mathrm{T}_{3}$ can prevent or recover the effects of SD on body weight loss (Barrett et al. 2007, Murphy et al. 2012). Additionally, torpor (a daily survival state of reduced metabolic activity during SD) is also prevented in these centrally $\mathrm{T}_{3}$-supplemented hamsters. Intact sympathetic signalling is required for torpor in mice and hamsters (Swoap \& Weinshenker 2008, Braulke \& Heldmaier 2010) and of particular importance is recovery from torpor via sympathetic activation of brown fat. Therefore, it is postulated that hypothalamic $\mathrm{T}_{3}$ maintains a level of 'sympathetic tone' to prevent torpor, despite receiving seasonally driven signalling (Murphy et al. 2012).

Several studies have started to unravel the underlying central mechanism (Bechtold \& Loudon 2007), which begins with the detection of a changing day length by the retino-hypothalamic pathway, triggering the output of melatonin from the pineal gland to target tissues. It has been hypothesised that this hormone then facilitates the release of TSH $\beta$ from the pars tuberalis (Hanon et al. 2008), which in turn acts on the tanycytes, specialised ependymal cells lining the third ventricle of the hypothalamus (reviewed in Morgan \& Hazlerigg (2008), Ebling (2010) and Dupre (2011)). The tanycytes are well known to play a crucial role in the regulation of hypothalamic thyroid hormone levels; in the Siberian hamster, an up-regulation of Dio3 in tanycytes is observed, with the highest Dio3 expression coinciding with the nadir in seasonal body weight (Barrett et al. 2007).

Despite the conclusive demonstration that changes in the availability of $\mathrm{T}_{3}$ in the hypothalamus are crucial to facilitating seasonal changes in body weight, the downstream cellular and molecular targets of $\mathrm{T}_{3}$ action in the seasonal regulation of energy metabolism still remain enigmatic.

\section{Thyroid hormone modulates cardiovascular function via the brain}

In addition to seasonal or acute metabolic adaptations, the brain also rapidly adjusts heart rate and blood pressure by the autonomic nervous system, for instance upon alterations in environmental temperature (Swoap et al. 2008). As the symptoms of hyperthyroidism and catecholamine excess are clinically very similar, it was assumed for a long time that thyroid hormone might interact with the autonomic innervation of the heart. However, due to the very profound direct effects of the hormone on the cardiovascular system (Klein \& Ojamaa 2001, Kahaly \& Dillmann 2005), the subtle effects on the autonomic nervous system were often masked in experimental paradigms. More recent technologies, such as spectral analysis of heart rate variability, finally demonstrated a correlation between thyroid hormone levels and cardiac autonomic activity (Cacciatori et al. 2000, Burggraaf et al. 2001, Chen et al. 2006). Further studies on animal models showed that indeed thyroid hormone receptor $\alpha 1$ signalling is required for the autonomic adaptations of heart rate to stress, activity and temperature (Mittag et al. 2010). Despite the technological progress in the investigation of autonomic nervous system function, the underlying molecular mechanisms as well as the cellular targets remain poorly defined.

\section{What are the cellular and molecular targets of thyroid hormone action in the brain?}

The neuroanatomical substrates of thyroid hormone in the central control of the autonomic nervous system are largely enigmatic, often because the experimental techniques used are not precise enough to allow a resolution beyond the level of anatomical nuclei. For instance, a simple stereotaxic injection of thyroid hormone into the brain is likely to target all cells in that area and might even diffuse across the borders of neuroanatomical nuclei with additional side effects. Similarly, transfections or elimination of thyroid hormone receptors without cellular restrictions are expected to give rise to the same problem. Therefore, such an approach can only provide initial clues to the rough anatomical areas that might respond to thyroid hormone; it is suboptimal, however, in identifying specific cell populations and subsequently the underlying molecular mechanisms.

Consequently, to date, only a handful of thyroid hormone target genes have been identified at the cellular level in the brain (Thompson \& Potter 2000, Santisteban \& Bernal 2005). Some of them might indeed be implicated in the developmental defects caused by maternal or congenital hypothyroidism such as problems with migration, incomplete axonal myelination or reduced dendrite and synapse formation (Fig. 1A) - while others could partially explain the acute effects of thyroid hormone on central homeostasis (Fig. 1B).

Nevertheless, novel model systems are sorely needed to investigate thyroid hormone signalling at the cellular 
rather than the anatomical level and on the whole genome rather than the individual gene level. A big obstacle in the design of such studies is the poor quality of the commercially available TR antibodies; they often also give strong cytosolic staining, which is unlikely to result from specific binding to nuclear hormone receptors and rather indicates unspecific cross-reactivity. This lack of specificity in turn is likely to result in false positives in assays that depend on antibody quality such as chromatin immunoprecipitation or cell labelling by immunohistochemistry.

To overcome this obstacle, a novel animal model has been established recently, which expresses a TR $\alpha 1-G F P$ fusion protein. Subsequent analyses of these mice revealed that TR 1 is expressed in almost all postmitotic neurons (Wallis et al. 2010) with no detectable signal outside the nucleus. As the chimeric receptor has only minimal effects on the regulation of thyroid hormone target genes, this animal model will also be of value for chromatin immunoprecipitation experiments given the high quality of the available GFP antibodies.

Regarding the postmitotic expression of TR 1 in almost all neurons, it is not surprising that thyroid hormone exerts a plethora of effects via the CNS and that it can act on migration and maturation during brain development as well as on neuronal function in the adult brain. More importantly, however, this finding underlines the necessity of cell-specific approaches to unravel thyroid hormone signalling in the brain, as virtually all neurons in an anatomical nucleus, whether inhibitory or excitatory, can be expected to respond to alterations in thyroid hormone levels, maybe even with opposing effects.

\section{Conclusion}

Recent findings clearly demonstrate that thyroid hormone regulates peripheral homeostasis via central actions. This includes the cardiovascular system and metabolism, where the hormone seems to act in synergy with its peripheral actions, but also species-specific phenomena such as seasonality. However, all experimental paradigms that aim to address thyroid hormone actions on homeostasis need to carefully distinguish the central from the peripheral actions and the developmental from the acute actions of the hormone.

As thyroid hormone receptor is expressed in almost every postmitotic neuron, the step from the neuroanatomical to the cellular level will be of particular relevance to understand the precise nature of thyroid hormone signalling in the brain. As genetic and neuroanatomical techniques have greatly advanced during the recent years, we are now equipped with the right tools to address these questions - in particular, the availability of several Cre mouse strains with

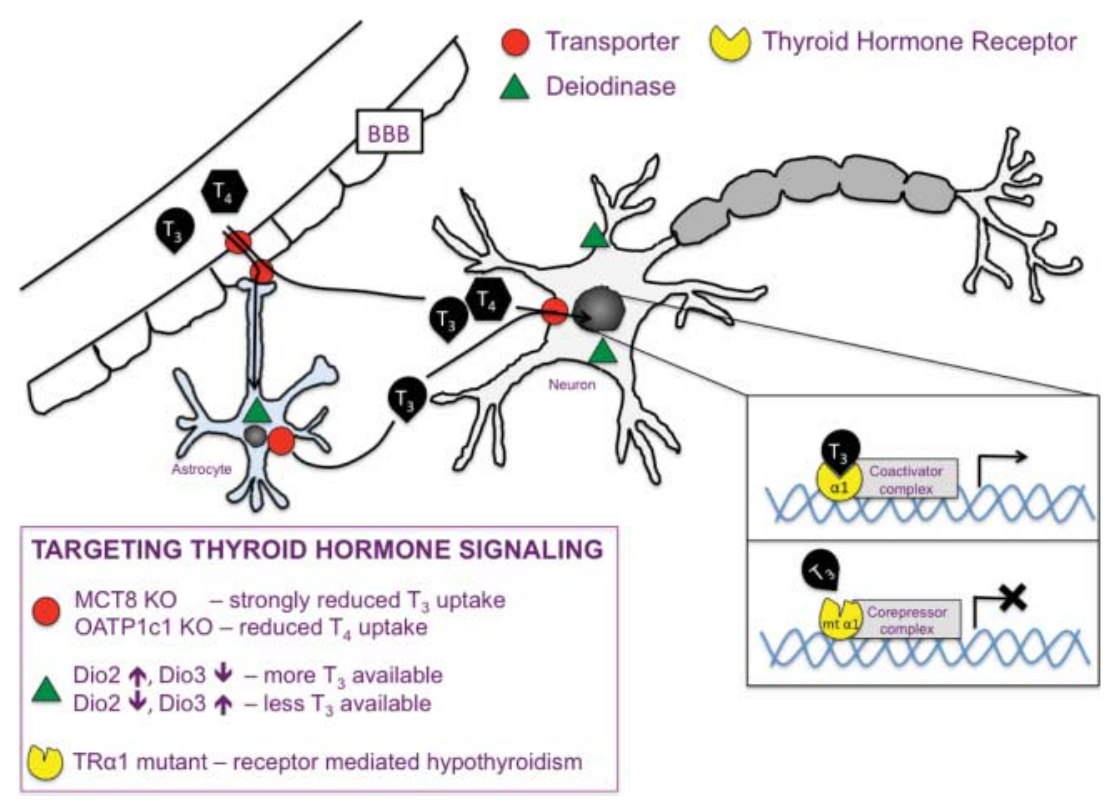

Figure 2 Targeting thyroid hormone signalling in the brain. Several different molecules such as transporters (circle), deiodinases (triangle) and receptors (pacman) are involved in controlling thyroid hormone actions in the brain (Heuer et al. 2005, Dumitrescu et al. 2006, Trajkovic et al. 2007, Wallis et al. 2010, Mayerl et al. 2012). BBB, blood brain barrier; Dio2/3, deiodinase type II or III; MCT8, monocarboxylate transporter 8; Oatp1c1, organic anion transporting polypeptide 1c1; TR, thyroid hormone receptor. 
appropriate neuronal subtype specificity (Picou et al. 2012). Even more importantly, our knowledge on thyroid hormone signalling allows the design of genetic strategies to modulate hormonal action in a cell-specific manner (Fig. 2). In contrast to many other endocrine systems, we know about hormone activation, inactivation, selective transport and receptor function, which could be used in experimental paradigms such as

- the manipulation of thyroid hormone availability on the cellular level using specific neuronal promoters to reduce thyroid hormone import, e.g. by a conditional Mct8 knockout,

- the combination of a specific Cre strain with the stereotaxic injection of a virus carrying a Cre-activatable mutant $T R \alpha 1$ gene, or

- the isolation of defined neuronal populations from hypo- or hyperthyroid mice using fluorescence-activated cell sorting (Guez-Barber et al. 2012).

These types of experiments will allow identification of the effects of thyroid hormone on specific cell populations involved in the control of homeostasis and moreover will contribute to the unravelling of the underlying molecular mechanisms. Despite the fact that the toy itself is more than a century old, the playground for thyroid hormone has never been more promising.

\section{Declaration of interest}

The authors declare that there is no conflict of interest that could be perceived as prejudicing the impartiality of the review reported.

\section{Funding}

This work was supported by the Swedish Research Council Vetenskapsrådet (grant FS-2009-510 to J M, 524-2011-6826 to A W).

\section{References}

Alvarez-Dolado M, Iglesias T, Rodriguez-Pena A, Bernal J \& Munoz A 1994 Expression of neurotrophins and the trk family of neurotrophin receptors in normal and hypothyroid rat brain. Brain Research. Molecular Brain Research 27 249-257. (doi:10.1016/0169328X (94)90007-8)

Barrett P, Ebling FJ, Schuhler S, Wilson D, Ross AW, Warner A, Jethwa P, Boelen A, Visser TJ, Ozanne DM et al. 2007 Hypothalamic thyroid hormone catabolism acts as a gatekeeper for the seasonal control of body weight and reproduction. Endocrinology 148 3608-3617. (doi:10.1210/en.2007-0316)

Bechtold DA \& Loudon ASI 2007 Hypothalamic thyroid hormones: mediators of seasonal physiology. Endocrinology 148 3605-3607. (doi:10.1210/en.2007-0596)

Bernal J 2007 Thyroid hormone receptors in brain development and function. Nature Clinical Practice. Endocrinology $\mathcal{E}$ Metabolism 3 249-259. (doi:10.1038/ncpendmet0424)
Bianco AC \& Kim BW 2006 Deiodinases: implications of the local control of thyroid hormone action. Journal of Clinical Investigation 116 2571-2579. (doi:10.1172/JCI29812)

Braulke LJ \& Heldmaier G 2010 Torpor and ultradian rhythms require an intact signalling of the sympathetic nervous system. Cryobiology 60 198-203. (doi:10.1016/j.cryobiol.2009.11.001)

Bochukova E, Schoenmakers N, Agostini M, Schoenmakers E, Rajanayagam O, Keogh JM, Henning E, Reinemund J, Gevers E, Sarri M et al. 2012 A mutation in the thyroid hormone receptor alpha gene. New England Journal of Medicine 366 243-249. (doi:10.1056/NEJMoa1110296)

Burggraaf J, Tulen JH, Lalezari S, Schoemaker RC, De Meyer PH, Meinders AE, Cohen AF \& Pijl H 2001 Sympathovagal imbalance in hyperthyroidism. American Journal of Physiology. Endocrinology and Metabolism 281 E190-E195.

Cacciatori V, Gemma ML, Bellavere F, Castello R, De Gregori ME, Zoppini G, Thomaseth K, Moghetti P \& Muggeo M 2000 Power spectral analysis of heart rate in hypothyroidism. European Journal of Endocrinology 143 327-333. (doi:10.1530/ eje.0.1430327)

Chen JL, Chiu HW, Tseng YJ \& Chu WC 2006 Hyperthyroidism is characterized by both increased sympathetic and decreased vagal modulation of heart rate: evidence from spectral analysis of heart rate variability. Clinical Endocrinology 64 611-616. (doi:10.1111/j. 1365-2265.2006.02514.x)

Davis PJ \& Davis FB 1996 Nongenomic actions of thyroid hormone. Thyroid 6 497-504. (doi:10.1089/thy.1996.6.497)

Decherf S, Seugnet I, Kouidhi S, Lopez-Juarez A, Clerget-Froidevaux MS \& Demeneix BA 2010 Thyroid hormone exerts negative feedback on hypothalamic type 4 melanocortin receptor expression. PNAS 107 4471-4476. (doi:10.1073/pnas.0905190107)

Dumitrescu AM, Liao XH, Weiss RE, Millen K \& Refetoff S 2006 Tissue-specific thyroid hormone deprivation and excess in monocarboxylate transporter (mct) 8-deficient mice. Endocrinology 147 4036-4043. (doi:10.1210/en.2006-0390)

Dupre SM 2011 Encoding and decoding photoperiod in the mammalian pars tuberalis. Neuroendocrinology 94 101-112. (doi:10.1159/000328971)

Ebling FJP 2010 Photoperiodic regulation of puberty in seasonal species. Molecular and Cellular Endocrinology 324 95-101. (doi:10.1016/j.mce.2010.03.018)

de Escobar GM, Obregon MJ \& del Rey FE 2007 Iodine deficiency and brain development in the first half of pregnancy. Public Health Nutrition 10 1554-1570. (doi:10.1017/S1368980007360928)

Fliers E, Klieverik LP \& Kalsbeek A 2010 Novel neural pathways for metabolic effects of thyroid hormone. Trends in Endocrinology and Metabolism 21 230-236. (doi:10.1016/j.tem.2009.11.008)

Forhead AJ, Cutts S, Matthews PA \& Fowden AL 2009 Role of thyroid hormones in the developmental control of tissue glycogen in fetal sheep near term. Experimental Physiology 94 1079-1087. (doi:10.1113/expphysiol.2009.048751)

Friesema EC, Jansen J, Milici C \& Visser TJ 2005 Thyroid hormone transporters. Vitamins and Hormones 70 137-167. (doi:10.1016/ S0083-6729(05) 70005-4)

Guez-Barber D, Fanous S, Harvey BK, Zhang Y, Lehrmann E, Becker KG, Picciotto MR \& Hope BT 2012 FACS purification of immunolabeled cell types from adult rat brain. Journal of Neuroscience Methods 203 10-18. (doi:10.1016/j.jneumeth.2011.08.045)

Hanon EA, Lincoln GA, Fustin JM, Dardente H, Masson-Pevet M, Morgan PJ \& Hazlerigg DG 2008 Ancestral TSH mechanism signals summer in a photoperiodic mammal. Current Biology 18 1147-1152. (doi:10.1016/j.cub.2008.06.076)

Heuer H, Maier MK, Iden S, Mittag J, Friesema EC, Visser TJ \& Bauer K 2005 The monocarboxylate transporter 8 linked to human psychomotor retardation is highly expressed in thyroid hormonesensitive neuron populations. Endocrinology 146 1701-1706. (doi:10.1210/en.2004-1179) 
Huang SA 2005 Physiology and pathophysiology of type 3 deiodinase in humans. Thyroid 15 875-881. (doi:10.1089/thy.2005.15.875)

Kahaly GJ \& Dillmann WH 2005 Thyroid hormone action in the heart. Endocrine Reviews 26 704-728. (doi:10.1210/er.2003-0033)

Kim B 2008 Thyroid hormone as a determinant of energy expenditure and the basal metabolic rate. Thyroid 18 141-144. (doi:10.1089/thy. 2007.0266)

Klein I \& Ojamaa K 2001 Thyroid hormone and the cardiovascular system. New England Journal of Medicine 344 501-509. (doi:10.1056/ NEJM200105103441901)

Klieverik LP, Janssen SF, van Riel A, Foppen E, Bisschop PH, Serlie MJ, Boelen A, Ackermans MT, Sauerwein HP, Fliers E et al. 2009 Thyroid hormone modulates glucose production via a sympathetic pathway from the hypothalamic paraventricular nucleus to the liver. PNAS 106 5966-5971. (doi:10.1073/pnas.0805355106)

Lechan RM \& Fekete C 2006 The TRH neuron: a hypothalamic integrator of energy metabolism. Progress in Brain Research 153 209-235. (doi:10.1016/S0079-6123(06)53012-2)

Liu YY, Schultz JJ \& Brent GA 2003 A thyroid hormone receptor alpha gene mutation $(\mathrm{P} 398 \mathrm{H})$ is associated with visceral adiposity and impaired catecholamine-stimulated lipolysis in mice. Journal of Biological Chemistry 278 38913-38920. (doi:10.1074/jbc. M306120200)

Lopez M, Varela L, Vazquez MJ, Rodriguez-Cuenca S, Gonzalez CR, Velagapudi VR, Morgan DA, Schoenmakers E, Agassandian K, Lage R et al. 2010 Hypothalamic AMPK and fatty acid metabolism mediate thyroid regulation of energy balance. Nature Medicine 16 1001-1008. (doi:10.1038/nm.2207)

Magnus-Levy A 1895 Uber den respiratorischen gaswechsel unter dem einfluss der thyroidea sowie unter verschiedenen pathologischen zustanden. Berliner Klinische Wochenschrift 34 650-652.

Mayerl S, Visser TJ, Darras VM, Horn S \& Heuer H 2012 Impact of Oatplc1 deficiency on thyroid hormone metabolism and action in the mouse brain. Endocrinology 153 1528-1537. (doi:10.1210/en. 2011-1633)

Mittag J 2009 Peripheral regulation of energy metabolism by thyroid hormone. Hot Thyroidology. HT02/09.

Mittag J, Friedrichsen S, Heuer H, Polsfuss S, Visser TJ \& Bauer K 2005 Athyroid Pax $8^{-/-}$mice cannot be rescued by the inactivation of thyroid hormone receptor alphal. Endocrinology 146 3179-3184. (doi:10.1210/en.2005-0114)

Mittag J, Davis B, Vujovic M, Arner A \& Vennstrom B 2010 Adaptations of the autonomous nervous system controlling heart rate are impaired by a mutant thyroid hormone receptor-alphal. Endocrinology 151 2388-2395. (doi:10.1210/en.2009-1201)

Morgan PJ \& Hazlerigg DG 2008 Photoperiodic signalling through the melatonin receptor turns full circle. Journal of Neuroendocrinology 20 820-826. (doi:10.1111/j.1365-2826.2008.01724.x)

Murphy M, Jethwa PH, Warner A, Barrett P, Nilaweera KN, Brameld JM \& Ebling FJP 2012 Effects of manipulating hypothalamic triiodothyronine concentrations on seasonal body weight and torpor cycles in Siberian hamsters. Endocrinology 153 101-112. (doi:10.1210/en.2011-1249)

Picou F, Fauquier T, Chatonnet F \& Flamant F 2012 A bimodal influence of thyroid hormone on cerebellum oligodendrocyte differentiation. Molecular Endocrinology 26 608-618. (doi:10.1210/ me.2011-1316)

Sainsbury A \& Zhang L 2011 Role of the hypothalamus in the neuroendocrine regulation of body weight and composition during energy deficit. Obesity Reviews 13 234-257. (doi:10.1111/j.1467789X.2011.00948.x)
Santisteban P \& Bernal J 2005 Thyroid development and effect on the nervous system. Reviews in Endocrine $\mathcal{E}$ Metabolic Disorders 6 217-228. (doi:10.1007/s11154-005-3053-9)

Short KR, Nygren J, Barazzoni R, Levine J \& Nair KS 2001 T(3) increases mitochondrial ATP production in oxidative muscle despite increased expression of UCP2 and -3. American Journal of Physiology. Endocrinology and Metabolism 280 E761-E769.

Silva JE 2006 Thermogenic mechanisms and their hormonal regulation. Physiological Reviews 86 435-464. (doi:10.1152/physrev. 00009.2005)

Sjogren M, Alkemade A, Mittag J, Nordstrom K, Katz A, Rozell B, Westerblad H, Arner A \& Vennstrom B 2007 Hypermetabolism in mice caused by the central action of an unliganded thyroid hormone receptor alpha1. EMBO Journal 26 4535-4545. (doi:10.1038/sj.emboj.7601882)

Swoap SJ \& Weinshenker D 2008 Norepinephrine controls both torpor initiation and emergence via distinct mechanisms in the mouse. PLoS ONE 3 e4038. (doi:10.1371/journal.pone.0004038)

Swoap SJ, Li C, Wess J, Parsons AD, Williams TD \& Overton JM 2008 Vagal tone dominates autonomic control of mouse heart rate at thermoneutrality. American Journal of Physiology. Heart and Circulatory Physiology 294 H1581-H1588. (doi:10.1152/ajpheart.01000.2007)

Thompson CC \& Potter GB 2000 Thyroid hormone action in neural development. Cerebral Cortex 10 939-945. (doi:10.1093/cercor/10. 10.939)

Trajkovic M, Visser TJ, Mittag J, Horn S, Lukas J, Darras VM, Raivich G, Bauer K \& Heuer H 2007 Abnormal thyroid hormone metabolism in mice lacking the monocarboxylate transporter 8. Journal of Clinical Investigation 117 627-635. (doi:10.1172/JCI28253)

Varela L, Martinez-Sanchez N, Gallego R, Vazquez MJ, Roa J, Gandara M, Schoenmakers E, Nogueiras R, Chatterjee K, Tena-Sempere $\mathrm{M}$ et al. 2012 Hypothalamic mTOR pathway mediates thyroid hormone-induced hyperphagia in hyperthyroidism. Journal of Pathology 227 209-222. (doi:10.1002/path.3984)

Visser WE, Friesema EC \& Visser TJ 2011 Minireview: thyroid hormone transporters: the knowns and the unknowns. Molecular Endocrinology 25 1-14. (doi:10.1210/me.2010-0095)

Vujovic M, Nordstrom K, Gauthier K, Flamant F, Visser TJ, Vennstrom B \& Mittag J 2009 Interference of a mutant thyroid hormone receptor alphal with hepatic glucose metabolism. Endocrinology 150 2940-2947. (doi:10.1210/en.2008-1085)

Wallis K, Dudazy S, van Hogerlinden M, Nordstrom K, Mittag J \& Vennstrom B 2010 The thyroid hormone receptor alphal protein is expressed in embryonic postmitotic neurons and persists in most adult neurons. Molecular Endocrinology 24 1904-1916. (doi:10.1210/ me.2010-0175)

Warner A, Jethwa PH, Wyse CA, I'Anson H, Brameld JM \& Ebling FJ 2010 Effects of photoperiod on daily locomotor activity, energy expenditure, and feeding behavior in a seasonal mammal. American Journal of Physiology. Regulatory, Integrative and Comparative Physiology 298 R1409-R1416. (doi:10.1152/ajpregu.00279.2009)

Yen PM 2001 Physiological and molecular basis of thyroid hormone action. Physiological Reviews 81 1097-1142.

Yen PM, Ando S, Feng X, Liu Y, Maruvada P \& Xia X 2006 Thyroid hormone action at the cellular, genomic and target gene levels. Molecular and Cellular Endocrinology 246 121-127. (doi:10.1016/j. mce.2005.11.030)

Received in final form 2 May 2012

Accepted 14 May 2012

Made available online as an Accepted Preprint 14 May 2012 